\title{
Book Review: Contemporary Language Motivation Theory - 60 Years Since Gardner and Lambert (1959) by Ali H. Al-Hoorie and Peter D. Maclntyre
}

\author{
Dorota Záborská, Heian Jogakuin University \\ dorota.matsumoto@gmail.com
}

Whether it is a truism or a cliché, we stand on the shoulders of giants. Professor Robert Gardner is certainly one of them. The year 2019 marked 60 years since the publication of his seminal paper, Motivational Variables in Second Language Acquisition, written together with Wallace E. Lambert and published in the Canadian Journal of Psychology in 1959. The paper is widely acknowledged as the beginning of L2 motivation research, and to borrow Dörnyei’s words introducing this anthology, "[it] is not only important because it was a historical milestone and offered fertile ground in which subsequent research could grow, but also because it is still relevant" (Dörnyei, 2020, p. xxi). Having Dörnyei's blessing, and with the caliber of contributors in this anthology, the relevance of Gardner's legacy of research is without question.

In this festschrift, editors Ali H. Al-Hoorie and Peter D. MacIntyre bring together twenty-six scholars in the fields of applied linguistics, social psychology, and sociology to honor the career and research contributions of Robert
Gardner. Each contribution connects to, develops, and builds upon the ideas of Gardner and Lambert, and links them to current trends and developments related to contemporary language motivation research. Thus, this collection of papers will delight and catch the attention of a wide readership from graduate students to practitioners to established researchers alike.

In this anthology, fourteen chapters are organized into four categories: 1) Second Language Development/Applied Linguistics, 2) Social Psychology/Sociology, 3) Historical/Methodological Issues, and finally 4) Discussants, in which invited scholars reflect on Gardner's considerable research contributions from various perspectives. Preceding the first section, the collection begins with a foreword written by Dörnyei, where he attributes the development of his own thinking about L2 motivation, particularly, his L2 Motivational Self System framework, to Gardner's theory of integrative motivation (Dörnyei, 2020). 
Subsequently, editors Al-Hoorie and MacIntyre provide us with an introduction to this anthology and explain some of the most significant ways in which Gardner's work has influenced research on language motivation. Then, readers are treated to a chapter by Gardner himself. In his chapter, he reflects on the history of research related to attitudes and motivation in Second Language Acquisition (SLA) and Foreign Language Acquisition (FLA) that he and his colleagues have conducted over the past 60 years. He divides the history of language motivation research into three parts: ancient history, early history, and modern history and overviews what characterizes each period. Gardner also highlights several studies which have tested hypotheses about the role of motivation in SLA. Additionally, he also looks at the development of his Attitude/Motivation Test Battery (AMTB) (Gardner, 1985), as well as several of the underlying motivational models at the time. This chapter will be particularly beneficial for student audiences or for those who may be unfamiliar with Gardner; it serves as an overview and introduction to Gardner's legacy of research as well as motivation research more generally.

Following Gardner's chapter is the first main section, Second Language Development/Applied Linguistics. This section consists of four chapters, and begins with a contribution from Gregersen, MacIntyre, and Ross (Chapter 1), who explore connections between Gardner's theory of integrative motivation and Seligman's PERMA ( $\mathrm{P}$ Positive Emotion, E - Engagement, R - Relationships, $\mathrm{M}$ Meaning, A - Accomplishments) framework of well-being. The authors explore how a combination of these two theories can lead to new research propositions and key attributes that both frameworks share. Furthermore, they propose three specific ways in which Gardner's constructs of integrativeness, attitudes towards language learning, and motivation can be empirically tested.

In Chapter 2, Bernaus reports on several studies, including some of her own, focusing on learners' motivation and second language learning from the perspective of Gardner's socio-educational model within a European context. Specifically, she focuses on research done in two multilingual regions in Catalonia and the Basque Country. In these studies, she also highlights teachers' affective characteristics, motivations, and their job satisfaction as influences on classroom strategies, and further, discusses how teacher and learner motivation is reciprocal. Examining how these factors affect learners and teachers' motivation in the classroom, Bernaus suggests that project work and content-based teaching may serve as effective pedagogical approaches, in part because of their potential to foster community.

In the next chapter, MacIntyre, Dewaele, Macmillan, and Li (Chapter 3), report findings from two of their empirical studies which explored the emotional core of Gardner's socio-educational model. The first study involves secondary level Chinese learners of English and the other uses data from an international web survey examining correlations between dimensions of Gardner's AMTB (Gardner, 1985) and the emotions measured by Positive and Negative Affect Schedule (PANAS) (Watson et al., 1988). In line with Gardner's thinking, the researchers observe that emotional processes underlie attitudes towards language learning, with positive emotions being consistently correlated across these culturally diverse groups of participants. Importantly, the authors suggest that positive emotion supports Gardner's notion of integrative motivation and argue the necessity of fostering positive emotion in language classrooms.

In the last chapter of the first section, Lantolf and Swain (Chapter 4) highlight the substantial impact of Gardner and Lambert's work and discuss how influential their research was and still is in drawing the attention of applied linguistics to non-cognitive factors related to second language learning. They themselves further explore the affective dimensions of motivation by utilizing the concept of perezhivanie from the theoretical proposals of a Russian psychologist Lev Vygotsky. After a careful clarification of the meanings entailed in perezhivanie, they advocate for the usage of the Russian term itself, rather than using its English translation. To detail the utility of perezhivanie, the authors reflect on several interesting L2 studies with perezhivanie used as a central lens and re-examine additional studies that could also be analyzed through this lens. Then, they suggest and call for activities in language curricula being designed in such a way that they can help learners attain better language proficiency by helping them understand the ways of expressing emotions in the language of particular language groups. No matter the readers' context, all four chapters in Part I offer helpful insights for L2 researchers and classroom practitioners. 
Part II contains three chapters related to Social Psychology and Sociology, which takes readers beyond the language classroom. In the first chapter in this section, Rubenfeld and Clément (Chapter 5) summarize several decades of research on how the macro-social context impacts SLA. They start with Clément's socio-contextual model (1980, 1986), which he extended from Gardner's socio-educational model. Clément's socio-contextual model is an approach to SLA from the perspective of the social psychology of intergroup relations between first and second language groups. In this model, his concept of ethnolinguistic vitality, i.e., the social and structural characteristics crucial for the survival of a language community, has an outsized influence on an individual's motivational processes in approaching or avoiding a second language community. Rubenfeld and Clément suggest this can impact how motivated an individual is to learn a language and also to integrate into that community.

Rubenfeld and Clément also note that Gardner's work often highlighted the importance of non-linguistic outcomes associated with L2 classroom learning. With this in mind, the authors overview research related to several of these non-linguistic outcomes such as its impact on individuals' social identities, psychological and socio-cultural adjustment linked to linguistic confidence, and formation of cultural representations, or "mental and public representations of a cultural community” (Rubenfeld \& Clément, 2020, p. 119). Then they continue to explore the concepts of intercultural competence, in-group/out-group dynamics and discrimination, willingness to communicate, and linguistic intergroup bias. This chapter provides an excellent and accessible overview of a number of these somewhat complicated concepts clearly summarized for the reader.

In the next chapter in Part II, Cila and Lalonde (Chapter 6) investigate the baby-naming motivations of bicultural parents living in multicultural and multilingual areas of Canada. To do so, they consider the role of integrative and instrumental motives, aspects of Gardner and Lambert's framework. They find that in some cases, parents choose names to try to retain and transmit their ethnic language and culture, foster parent-child connections, and nurture a sense of family and community, ethnic pride, and identity continuity. Yet, in other cases, parents may be motivated to adopt a name related to the mainstream culture or dominant language group, or sometimes to avoid name-based prejudice and discrimination.

The final chapter in Part II by Norton (Chapter 7) deals with her construct of investment, which she developed as a complement to Robert Gardner's construct of motivation. As Kramsch points out, "Norton's notion of investment in SLA has become synonymous with 'language learning commitment' and is based on a learner's intentional choice and desire" (Kramsch, 2013, as cited in Darvin \& Norton, 2016, p. 19). Gardner and Norton both analyze motivation from the perspective of three stakeholders: learners, teachers, and researchers. However, Gardner examines these stakeholders from a psychological perspective, while Norton looks at them from a sociological point of view.

Part III consists of five chapters and opens with Oxford's (Chapter 8) poetically titled, Snapshots in Time: Time in Gardner's Theory and Gardner's Theory across Time. On a personal note, I am a fan of Oxford's meticulously organized and systematic writing, so this might sound biased, but readers are in for yet another treat with this chapter. For this reason, I recommend visiting this chapter first when beginning an exploration of this book. Whether readers are already familiar with Gardner's research oeuvre, or have just been introduced to his work, Oxford's chapter provides an excellent segue into other chapters. Making use of a metaphor from photography, Oxford presents seven snapshots that are connected to Gardner's socio-educational model. She divides them into micro-perspectives (time in his model), and macro-perspectives (his model across time), explaining that " $[t]$ he snapshots here are expected to tell a rich story about different ways of looking at the socioeducational model; they are not a comprehensive presentation of Gardner's model” (Oxford, 2020, p. 172).

Next, Ushioda (Chapter 9) reflects on her own journey in becoming a qualitative researcher interested in language learning motivation. As she entered the field as a young researcher, Ushioda saw that Gardner was already one of the most influential figures researching language motivation. Now, as an established qualitative researcher herself, she revisits and re-evaluates the role and contribution of qualitative inquiry as it relates to motivation, which has greatly evolved and diversified conceptually as well as methodologically.

In the third chapter of Part III, Tremblay (Chapter 10) discusses the enormous contributions of Robert Gardner as 
it relates to research design, measurement, and statistics by reflecting on Gardner's quantitative background and the university courses on quantitative research methodology he developed and taught. Tremblay then continues with a recapitulation of several fundamental ideas from Gardner's graduate statistics courses including some of the techniques he developed that are still important to second language learning research. Finally, he suggests that modern techniques allow researchers to rely on the authority of computing algorithms, and as a result, he posits, researchers might not be as intimate with their data as they used to be. Yet, he remains hopeful "as long as curious researchers remain invested in understanding their tools in depth" (Tremblay, 2020, p. 230).

In the next chapter of Part III, Claro (Chapter 11) compares Gardner's integrativeness to Dörnyei's ideal L2 self. She observes Gardner's concept of integrativeness as L2 learner's identification with external referents, and Dörnyei's ideal L2 self as identification with internal referents, arguing thus that the ideal L2 self cannot replace integrativeness, and that these two concepts are in a complementary relationship. By examining both concepts, Claro provides a unified theory of identification, which Dörnyei agrees with and acknowledges in the foreword of this anthology. Another objective of Claro's chapter was to "suggest research directions to further develop and integrate their [Gardner's and Dörnyei's] contributions” (Claro, 2020, p. 253).

The final chapter of Part III, History, Philosophy and the Social Psychology of Language, was contributed by Edwards (Chapter 12). As its title suggests, the author "attempts to situate the social psychology of language within a very broad historical and philosophical context” (Edwards, 2020, p. 262). In this chapter, he offers some concise insights from the Classical period to the modern times and calls for the need "to acknowledge and pay more specific attention to the historical contextualization” of the undertakings of research involving the social psychology of language. Edwards also argues for the need to be interdisciplinary, even though going beyond the realm of one's narrow expertise is extremely difficult. Moreover, he claims "broadening of our enquiries" is unavoidable if researchers want to make meaningful contributions to the existing body of knowledge (Edwards, 2020, p. 275).
In Chapter 13, the first of the final section, discussants Hiver and Larsen-Freeman "offer a theorist's perspective on the contributions to this anthology in [Robert Gardner's] honor" (Hiver \& Larsen-Freeman, 2020, p. 285) by reflecting on how complex dynamic systems theory (CDST) relates to or is articulated by several chapters in the book. As the authors point out, "[t]he major contribution of CDST to scholars in the human and social disciplines is its way of thinking that represents a radically new foundation for scientific inquiry” (p. 288). By revisiting contributions in this volume, they point out how Gardner's socioeducational model, as well as the current L2 motivation scholarship inspired by Gardner, correspond to, and use systems thinking.

The final chapter finds discussant Horwitz (Chapter 14) contributing a brief but heartfelt personal reflection on how Robert Gardner's pioneering social-psychological research raised new applied questions about SLA, moving the field towards real language learners and teachers in real classrooms. Though this chapter appears toward the end of this anthology, it is also the kind of chapter that might be beneficial for readers to enjoy early as they embark on a dialogic reading journey with individual chapters.

The book closes with an epilogue: Gardner's FarReaching Impact Beyond Language Learning, written by Giles, who pays homage to his friend and academic colleague Robert Gardner. Giles points out Gardner’s other achievements that were instrumental in the modern evolution of intergroup communication and social psychology of language, as well as the importance of his contribution to Canadian scholarship. In addition to acknowledging Gardner for his research, Giles shares with the reader his collegiality and closeness with Bob (as he calls him) saying, "indeed, Bob is, in every sense, an academic's academic in that he has always been extraordinarily humble (albeit a staunch defender of his work when critiqued), a rigorous methodologist and empiricist, a pioneering statistician, and a sheer joy to be with” (2020, p. 310).

Rather than levying a critique per se, allow me to share my personal experience with this anthology. As a reviewer, I read every chapter carefully and deeply. Upon completion, I realized that I had befriended this text. When I first opened the book and saw the names of contributors, I thought that only a special person could attract such a remarkable array 
of scholars. As a result, I immediately and eagerly dove into the wide range of topics being offered. The subtitle, 60 Years Since Gardner and Lambert (1959) suggests a celebratory collection of papers. Yet, I feel that this book is not simply festschrift commemorating Professor Gardner's work from a retrospective view. This is because so many excellent researchers have been inspired to not only carry on Gardner's legacy, but to forge new ground in so many new directions as some chapters clearly demonstrate.
Finally, this book is certainly not meant to be read in one sitting. It deserves a prominent location on bookshelves, ready at arm's length for reference and inspiration. Depending on the reader's field of expertise, some chapters are challenging, yet ultimately all are accessible. In fact, the entire anthology kept me in a constant dialogue, and that I savored indeed. I'm confident that a wide readership will savor it, too.

\section{Notes on the author}

Dorota Záborská is an assistant professor at Heian Jogakuin (St. Agnes') University in Kyoto, Japan, and currently a PhD candidate at Waseda University. She has been teaching English at the primary, secondary, and tertiary levels for over 18 years. Her main research interests are the psychology of language learning, motivation, and learning foreign languages in the third age.

\section{REFERENCES}

Claro, J. (2020). Identification with external and internal referents: Integrativeness and the ideal L2 Self. In A. H. Al-Hoorie, \& P. D. MacIntyre (Eds.), Contemporary language motivation theory: 60 years since Gardner and Lambert (1959) (pp. 233-261). Multilingual Matters. https://doi.org/10.21832/9781788925211

Clément, R. (1980). Ethnicity, contact and communicative competence in a second language. In H. Giles, W. P. Robinson, \& P. Smith (Eds.), Language: Social psychological perspectives (pp. 147-154).

Pergamon Press. https://doi.org/10.1016/B978-008-024696-3.50027-2

Clément, R. (1986). Second language proficiency and acculturation: An investigation of the effects of language status and individual characteristics. Journal of Language and Social Psychology, 5, 271-290.

https://doi.org/10.1177/0261927X860050040 3

Darvin, R., \& Norton, B. (2016). Investment and Language Learning in the 21st Century. Langage et société, 157(3), 19-38. https://doi.org/10.3917/ls.157.0019

Dörnyei, Z. (2020). Foreword. In A. H. Al-Hoorie, \& P. D. MacIntyre (Eds.), Contemporary language motivation theory: 60 years since Gardner and Lambert (1959) (pp. xix-xxi). Multilingual Matters. https://doi.org/10.21832/9781788925211

Edwards, J. (2020). History, philosophy and the social psychology of language. In A. H. Al-Hoorie, \& P. D. MacIntyre (Eds.), Contemporary language motivation theory: 60 years since Gardner and Lambert (1959) (pp. 262-282). Multilingual Matters. https://doi.org/10.21832/9781788925211

Gardner, R. C. (1985). Social psychology and second language learning: The role of attitudes and motivation. Edward Arnold. https://doi.org/10.1017/s0272263100007634

Gardner, R. C., \& Lambert, W. E. (1959). Motivational variables in second-language acquisition. Canadian Journal of Psychology/Revue canadienne de psychologie, 13(4), 266-272. https://doi.org/10.1037/h0083787

Giles, H. (2020). Epilogue: Gardner’s far-reaching impact beyond language learning. In A. H. Al-Hoorie, \& P. D. MacIntyre (Eds.), Contemporary language motivation theory: 60 years since Gardner and Lambert (1959) (pp. 309-313). Multilingual Matters. https://doi.org/10.21832/9781788925211 
Hiver, P., \& Larsen-Freeman, D. (2020). Motivation: It is a relational system. In A. H. Al-Hoorie, \& P. D. MacIntyre (Eds.), Contemporary language motivation theory: 60 years since Gardner and Lambert (1959) (pp. 285-303). Multilingual Matters. https://doi.org/10.21832/9781788925211

Oxford, R. L. (2020). Snapshots in time: Time in Gardner's theory and Gardner's theory across time. In A. H. Al-Hoorie, \& P. D. MacIntyre (Eds.), Contemporary language motivation theory: 60 years since Gardner and Lambert (1959) (pp. 171-193). Multilingual Matters. https://doi.org/10.21832/9781788925211

\section{FULL PUBLICATION DETAILS}

Series Title: Psychology of Language Learning and Teaching

Title: Contemporary Language Motivation Theory.

Subtitle: 60 Years Since Gardner and Lambert (1959).

Editors: Ali H. Al-Hoorie and Peter D. Maclntyre

Date: 2020

Publisher: Multilingual Matters, Bristol, UK

Number of pages: 344

Number of chapters: 14

ISBN-10: 1788925181

ISBN-13: 9781788925181
Tremblay, P. F. (2020). Quantitative methods in second language learning motivation research: Gardner's contributions and some new developments. In A. H. Al-Hoorie, \& P. D. MacIntyre (Eds.), Contemporary language motivation theory: 60 years since Gardner and Lambert (1959) (pp. 212-232). Multilingual Matters. https://doi.org/10.21832/9781788925211

Watson, D., Clark, L. A., \& Tellegen, A. (1988). Development and validation of brief measures of positive and negative affect: The PANAS scales. Journal of Personality and Social Psychology, 54(6), 1063-1070. https://doi.org/10.1037/00223514.54.6.1063 